\title{
GH in the Central Nervous System: Lessons from the Growth Hormone Receptor Knockout Mouse
}

\author{
Elahu S. Gosney, Adam Jara, Amrita Basu and John J. Kopchick*
}

Edison Biotechnology Institute, Ohio University, Athens, Ohio 45701, USA

\begin{abstract}
Various central nervous system (CNS) tissues express both growth hormone (GH) and its receptor (GHR), including those involved in memory and cognition. Studies show the presence of GHR in the pituitary, choroid plexus, hypothalamus, hippocampus, pituitary and the spinal cord during development and, to a lesser extent, in adults. This expression implies a role of GH signaling in growth, development and functionality of the CNS. While data on the function of GH in the CNS is sparse, several studies have been conducted using the GHR knockout (-/-) mouse in order to better understand this role. Abnormal growth hormone signaling in humans is the cause of various diseases that include Laron syndrome, GH deficiency and acromegaly. This article will review the research conducted using the GHR-/- mouse on the role of GH signaling in the CNS. Where possible, we will attempt to contextualize the animal data with respect to human disease.
\end{abstract}

Keywords: Growth hormone, growth hormone receptor, central nervous system, acromegaly, Laron syndrome, brain.

\section{INTRODUCTION}

Studies in multiple species have shown expression of growth hormone $(\mathrm{GH})$ and $\mathrm{GH}$ receptors $(\mathrm{R})$ in multiple tissues of the central nervous system (CNS), implicating a role for GH signaling in the development and maintenance of neural tissues as well as memory and cognition [1-4]. Despite several lines of evidence from both in vivo and in vitro studies suggesting a role for GH in the CNS [5-8], the data are often contradictory. For example, studies of animals with elevated GH have shown improvements in memory and learning $[9,10]$, but similar results have been reported using animal models of reduced GH action [11-13]. Human subjects that are GH-deficient or resistant have not provided clarity, as some show normal or high intelligence and others have impaired cognitive function [14]. In addition, various mouse lines with altered GH signaling do not show obvious developmental or functional abnormalities in the CNS.

In humans, disease states exist for $\mathrm{GH}$ excess (acromegaly), GH deficiency (GHD) and GH insensitivity (Laron syndrome). In our laboratory and those of others, genetically engineered mouse lines (see Fig. 1) have been established that approximate these human diseases and have been useful in the study of the role of GH in the brain. Mice with excess GH production and secretion, such as the bovine $\mathrm{GH}$ transgenic animal (bGH), serve as models for acromegaly [15]. To approximate GHD, a transgenic dwarf mouse line has been generated that expresses a GHR antagonist (GHA) discovered in our laboratory [16]. Lastly, we have disrupted the GHR gene (GHR-/-) to generate a

*Address correspondence to this author at the Edison Biotechnology Institute, Ohio University, Athens, Ohio 45701, USA;

Tel: 1740593 4713; Fax: 1740593 4795;

E-mail:kopchick@biotech.ohio.edu mouse model of Laron syndrome [17]. It is the only mouse that has complete inhibition of GH-GHR signaling [17]. Together, these mice provide unique tools to study brain development and function in the presence or absence of GHR signaling from conception through old age. A review of the studies conducted with the GHR-/- dwarf mouse strain, along with data from several other animal models, will be the primary subject of this review, with reference to human disease where appropriate.

\section{EXPRESSION OF GHR IN THE BRAIN}

Early experimental evidence established the presence of GH binding sites in the hypothalamus of rabbits [18] and chickens [19]. Another study revealed the GH binding capacity of human brain tissue [20]. In this initial study, adult male and female brain specimens were obtained 15-48 hours post mortem at autopsy and assayed for radio-labeled human GH (hGH) binding capacity [20]. The choroid plexus possessed the highest amount of GH binding, followed by the pituitary, with no significant difference between males and females. In a follow-up study, GH binding in multiple areas of the human brain was examined as a function of age [21]. GH binding was observed in the choroid plexus, hippocampus, hypothalamus, pituitary, putamen and thalamus. Co-treatment with an excess of prolactin (PRL) was performed to exclude lactogenic binding sites, which also bind hGH. GH binding was again observed to be highest in the choroid plexus and the pituitary. A decline in GH binding as a function of age was observed in all areas except for the thalamus [21]. GH-binding sites have also been found in multiple regions of the rat brain by Zhai et al. [22], who showed binding sites in the choroid plexus, hypothalamus, hippocampus, pituitary and spinal cord with a decrease in binding in an age dependent manner. 


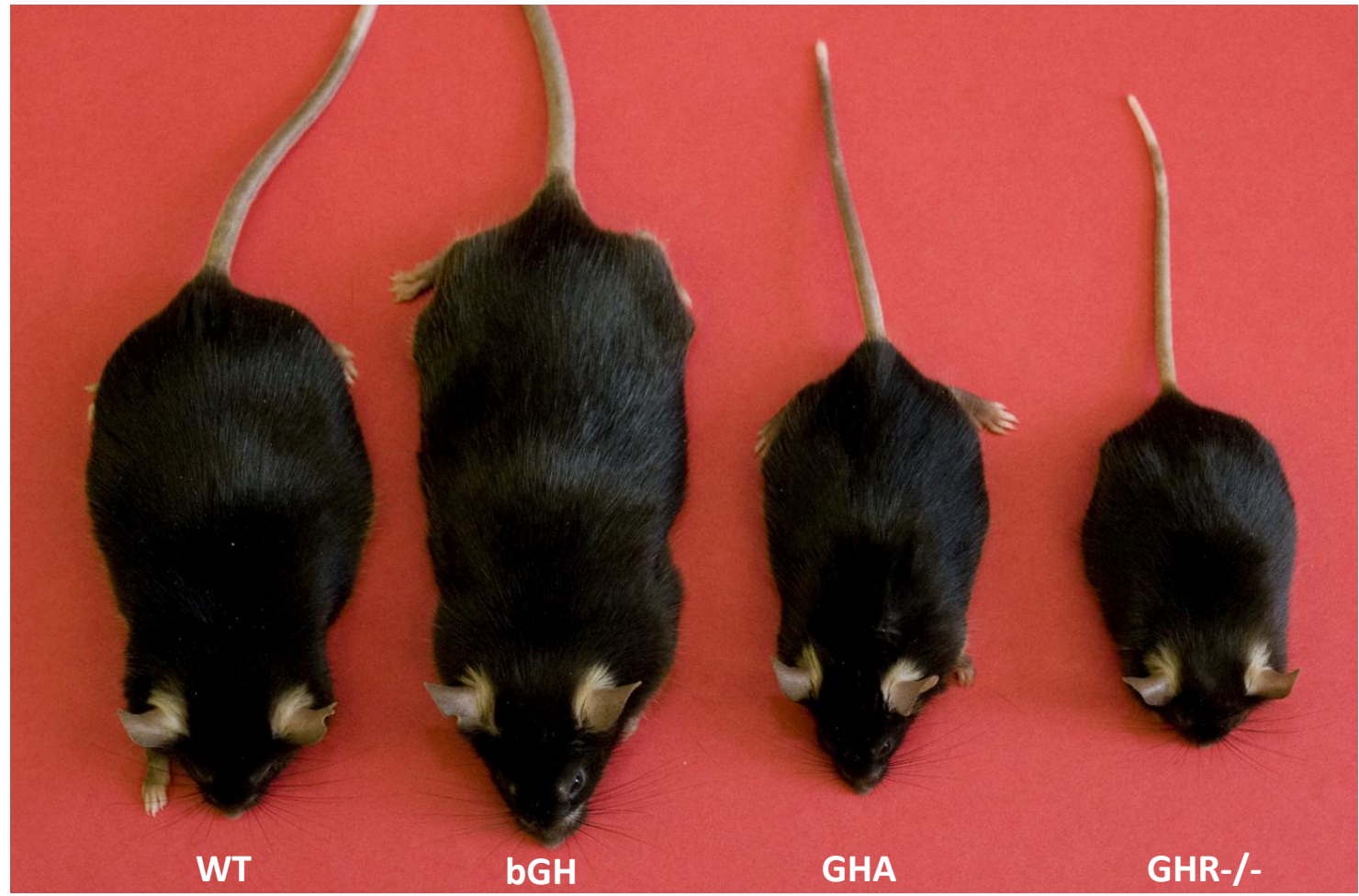

Fig. (1). Mice with alterations of GH action. Left to right are WT, bGH transgenic, GHA transgenic and GHR-/- mice.

The expression of GHR mRNA in the adult rat brain was shown by in situ hybridization, indicating that the GH binding sites that had been observed were likely due to specific binding to the GHR [23]. As anti-GHR antibodies became available, immunohistochemical techniques were used to analyze rat CNS tissue for GHR protein expression [1]. Rats at 2, 10, 25 and 90 days of age were examined. Ten day old rats showed near ubiquitous presence of GHR in varying degrees in the CNS, with immunoreactivity in all regions and cell types. There was a decline in GHR expression with increasing postnatal age of the animals. The presence of GHR mRNA was measured in all age groups. As with GHR immunoreactivity, there was a marked decline in GHR mRNA expression in the older groups of animals. As discussed by the authors [1], sites of GHR expression correlated with previously reported sites of insulin-like growth factor 1 (IGF-1) expression, implying that one of GH's actions in the brain may be the stimulation of local IGF-1 production. The presence of GHR mRNA in various regions of rat CNS was reported in the brain stem and spinal cord [24]. In situ hybridization experiments identified GHR in the arcuate nucleus of the hypothalamus, where GHR is known to be involved in the negative feedback loops that regulate GH production and secretion from somatotrophs of the pituitary. GHR was also found to be expressed in various regions of the pons, spinal cord and medulla oblongata. In these areas, GHR expression was detected in regions known to regulate food intake and sleep patterns, suggesting that GH may affect these biological processes by direct $\mathrm{GH}$ signaling in the brain [24]. The widespread presence of GH binding sites in various brain areas from multiple species indicates a biological role for $\mathrm{GH}$ in the CNS. The presence of GHR protein in multiple brain areas further indicates the capacity for GH signaling in the brain.

\section{GH IN BRAIN GROWTH AND DEVELOPMENT}

Growth hormone has long been hypothesized to be important for growth and development of the brain [3]. If GH has a critical role in brain growth, there should be obvious abnormalities in GHR-/- brain tissues. Most tissues in the GHR-/- animals show allometric scaling. The brain, however, is one of few organs that are disproportionate in size relative to the size of this dwarf animal. While smaller in absolute terms, brains of GHR-/- mice are approximately $50 \%$ larger than WT when normalized to body weight $[25$, 26]. Another model of reduced GH action, the dwarf GHA transgenic mouse, also displays an increase in brain weight relative to total body weight [27]. Concordant with this data, giant bGH transgenic mice display a decrease in brain size relative to body weight [28]. To further define the effect of GH disruption on brain growth, cross sectional areas were measured in GHR-/- mice [26]. In striatal sections, the cortical, subcortical and striatal cross sectional areas were all significantly smaller than WT in absolute terms, ranging from a $\sim 13 \%$ to $\sim 22 \%$ reduction in size. In hippocampal sections, the cortical and subcortical areas showed a $\sim 26 \%$ and $\sim 23 \%$ reduction in size, respectively, compared to WT controls. Cortical somatosensory thickness, however, was not different in GHR-/- animals. Even though GHR is widely expressed in the developing brain, these data indicate that $\mathrm{GH}$ is not a predominant regulator of early brain growth, which occurs largely prenatally, during a period of $\mathrm{GH}$-independent somatic growth. Therefore, the function of GHR in the developing brain is not clear. 


\section{PRENATAL AND PERINATAL MOTONEURON DEVELOPMENT}

Both GH and GHR have been shown to be widely expressed in the CNS of developing embryos, a finding highly suggestive of a role for $\mathrm{GH}$ signaling in neural development $[1,2,29]$. Additionally, $\mathrm{GH}$ has been shown to enhance proliferation of certain cells of the CNS. For example, incubation of fetal rat cerebral cortical cells with recombinant hGH results in increased proliferation in a time and dose-dependent manner [8]. GH is also reported to increase the proliferation of cortical cell precursors and astrocytes [8]. In mice, expression of GH and GHR peaks during embryonic day 14-18 (E14-E18), coincident with a period of CNS remodeling by way of a process known as programmed cell death (PCD), in which selective cell death and survival occur [30]. It is likely that this process involves both pro-apoptotic and protective anti-apoptotic signals. Given the well known anti-apoptotic actions of GH, and building upon previous work indicating neuroprotective properties of GH, Parsons et al. [30] hypothesized that GH may provide survival signals to selective cells during the process of PCD. To test this, they undertook studies using GHR-/- mice to investigate the potential neurotrophic role of $\mathrm{GH}$ in motoneurons during prenatal and perinatal CNS development [30]. They reasoned that if $\mathrm{GH}$ possesses an anti-apoptotic role in the developing CNS, then mice lacking GHR signaling would show obvious differences in brain cell apoptosis compared to WT animals. Three time points were examined for gross morphology, E13.5, E18.5 and postnatal day 2 (P2). Body weight, spinal cord volume, and muscle fiber diameter were found to be no different from controls. Additionally, no differences were reported in muscle fiber organization, innervations or motor axonal branching. Also, no obvious differences in motoneuron nuclei appearance and position, spinal cord appearance or motoneuron location within the lateral motor columns were found. Finally, to evaluate whether GH has a neurotrophic effect during PCD, the total number of motoneurons was quantified at the beginning and end of PCD. No difference in motoneuron number in the brachial and lumbar lateral motor columns between WT and GHR-/- embryos was reported [30]. While the number of cells was the same, the nuclear area (an indirect measure of cell size) was marginally but significantly smaller in GHR-/- mice at E13.5 and E18.5, indicative of a role of $\mathrm{GH}$ in motoneuron maturation. These data show only minor differences in motoneuron development in mice that possess complete disruption of GH-induced GHR signaling. This is somewhat unexpected given the fact that $\mathrm{GH}$ is expressed in the CNS during development and both in vitro and in vivo evidence suggest a role for GH in neuronal survival. One possibility is that an intact PRL signaling pathway, which shares many downstream components with GH signaling, is potentially able to compensate for the lack of GHR activity in GHR-/mice.

\section{NEURON POPULATIONS OF THE CNS}

The near ubiquitous expression of GH and GHRs within the brain during development [1] suggests that alterations of
GH signaling may affect various neuron populations in the adult animals. Turnley and colleagues demonstrated that suppressor of cytokine signaling-2 (SOCS2), a negative regulator of Janus kinase/signal transducers and activators of transcription (JAK/STAT) signaling, is expressed in neuroepithelial cells and neurons during development of the CNS [31]. SOCS2-/- mice, which have a loss of negative regulation of GHR-induced JAK/STAT signaling and thus increased GHR signaling, display a decrease of $\sim 30 \%$ in neuron density in the somatosensory cortex when compared to WT littermates [31]. Conversely, GHR-/- mice display a $23-26 \%$ increase over WT controls in overall neuron cell density in the same region, when quantified by immunohistochemical staining for neuronal nuclei protein, while total cell number was not different from WT [26].

Staining for specific types of neurons was performed in order to determine if the increased neural density was due to changes in specific subpopulations of cells [26]. Cortical interneuron subpopulations expressing calretinin and calbindin were both increased in density, along with cholinergic neurons in the striatum, while the density of parvalbumin positive neurons was not significantly altered in GHR-/- animals. Not only was there an increase in the density of calretinin and calbindin positive interneurons, but cell counts revealed that there was also an increase in the number of these cells in the GHR-/- cortex [26]. Astrocytes, on the other hand, were decreased in cell number in GHR-/animals. In addition, measures of cell soma size revealed a general decrease in cell size for both neurons and astrocytes.

These data indicate differential effects of GH signaling on subpopulations of CNS cells. While the GHR-/- brain is smaller than WT brain in absolute terms, it appears that in general, the same number of neurons are packed in at a greater density. On the other hand, glial cells were decreased in both size and number, resulting in a decreased glial to neuronal ratio in GHR-/- mice. Further studies are necessary to determine the neurological impact of this imbalance and to further define the exact roles that GH plays in astrocyte development and neurogenesis, as well as its role in various other sub-populations of neural cells.

\section{THE PITUITARY AND HYPOTHALAMUS}

The hypothalamic-pituitary axis functions in the coordinated release of endogenous hormones for the regulation of metabolism, gonadal function, and homeostasis. The anterior pituitary is composed of two populations of cells: basophiles and acidophiles. Basophilederived hormones include follicle-stimulating hormone (FSH), leutinizing hormone (LH), adrenocorticotropic hormone (ACTH), and thyroid stimulating hormone (TSH). Acidophile-derived hormones include GH and PRL. GH synthesis and secretion is tightly regulated by a number of feedback systems; several reviews [32-34] expound upon specific control mechanisms of endocrine GH synthesis and regulation. In short, neurons from the hypothalamus project to the pituitary where GH releasing hormone (GHRH) secretion stimulates GH gene expression and GH secretion while somatostatin (SRIF) secretion from another subset of hypothalamic neurons inhibits GH release. While GHRH and 
SRIF hypothalamic neurons represent primary sites of GH feedback control, there also exists a "long-loop" feedback by which GH synthesis and secretion is inhibited by serum IGF1. In addition, $\mathrm{GH}$ can attenuate its own production by participating in a "short-loop" feedback system in which GH acts via the hypothalamus to stimulate SRIF and inhibit GHRH secretion; GH also participates in an "ultra-short" feedback system in which GH acts directly upon somatotrophs. Ghrelin, a regulator of satiety, has also been shown to regulate $\mathrm{GH}$ production in the pituitary via the GH secretagogue receptor (GHS-R). In addition to these control mechanisms reviewed by Wong et al. [34], the organized three-dimensional network of somatotrophs within the pituitary may regulate $\mathrm{GH}$ secretion via direct cell to cell communication [35].

Feedback inhibition of GH production is predicated upon proper function of the GHR signaling cascade. Asa et al. [36] provided the first evidence that GH could directly inhibit GH production in somatotrophs. The study compared somatotroph morphology of giant transgenic mice expressing a GH agonist (E117L), dwarf transgenic mice expressing a GHA (G119K), and GHR-/- mice. The dwarf GHR-/- and GHA transgenic mice both demonstrated pituitary somatotroph hypersecretion. This was denoted by welldeveloped endoplasmic reticulae and large juxtanuclear Golgi complexes, in addition to increased populations of sparsely granulated focal-globular staining somatotrophs. The GHR-/- mice additionally exhibited mild pituitary somatotroph hyperplasia signified by an increase in the number of GH-immunoreactive cells and a disrupted reticulin network with obvious acini expansion. The giant transgenic mice, while grossly larger than their littermates, showed no morphological changes in the somatotroph population. In subsequent studies, an overall increase in the number of GH-immunoreactive cells in GHR-/- mice was confirmed $[37,38]$, with the total number of GH cells being disproportionately increased when normalized to body weight.

While populations of TSH and ACTH pituitary cells were not significantly different in GHR-/- mice when compared to wild type littermates [37], the number of PRL cells was greatly reduced. This is surprising because plasma PRL levels have been shown to be normal or elevated in GHR-/- mice [39]. Elevated serum PRL levels have also been demonstrated in Laron syndrome patients [40] and bGH mice [41]. These results imply that intact GHR signaling may be required to preserve normal PRL levels.

The loss of GH negative feedback in GHR-/- mice results in hypothalamic and pituitary stimulation of $\mathrm{GH}$ production. Neuropeptide Y (NPY) is a hypothalamic inhibitor of GHRH release. Peng et al. [38] established that GHR-/- mice express decreased levels of NPY mRNA and increased levels of GHRH mRNA. In addition, pituitary mRNA levels for GHRH receptor (GHRH-R) and GHS-R were significantly increased. Together these results further support the autoregulatory abilities of GH. Interestingly, NPY plays a role in stress management and may be central to the pathophysiology of psychiatric disorders such as anxiety and
PTSD. Decreased NPY levels have been associated with impaired memory, learning, and cognition [42].

In summary, the regulation of endocrine $\mathrm{GH}$ synthesis and secretion is complex - involving both central and peripherally derived modulators. GH feedback mechanisms are paramount to proper functioning of the pituitary. Loss of $\mathrm{GH}$ feedback causes changes in gross morphology of the pituitary, dysregulation of other pituitary hormones, and may influence psychiatric state and brain function.

\section{GH IN MEMORY \& COGNITION}

More than 30 years ago, animal studies began to examine the role of GH in memory [9]. In a mouse study, GH was shown to decrease memory retention when administered prior to a learning event [9]. The presence of GHR in brain regions that participate in memory formation and recall, the hippocampus and amygdala [1], is suggestive of a role for GH in memory and cognition. More recently, GH mRNA expression has been shown to be induced in the hippocampus by a memory formation exercise termed trace conditioning [43]. Data on cognitive function in human patients with abnormalities in GH signaling have provided contradictory data. In one cohort of 48 GHD patients, the intelligence quotient (IQ) was found to be lower than the control group and hence, an interrelation between $\mathrm{GH}$ deficiency and cognitive dysfunction was proposed [44]. A deficit in memory in these GHD patients was also observed. Other research, however, shows high or normal cognitive ability in GHD patients, as reviewed by Forshee [14].

The GHR-/- mice are long lived, surviving an average of $38-55 \%$ longer than WT controls [45]. Ames dwarf mice, another long-lived animal with impaired GH signaling, are similarly long-lived, surviving up to a year and a half longer than controls [46]. It is of interest to examine whether this extended longevity is a delay in the aging processes, which includes a decline in cognitive function, or simply an extension of "old age." This has been evaluated by examination of memory retention as a function of age in animals with altered $\mathrm{GH}$ action $[11,12]$. In a foot shock inhibitory avoidance test, 22-29 month old Ames dwarf mice performed as well as young WT or young Ames dwarf mice, while old WT mice had reduced performance compared to either young group [12]. In accordance with this data, young (6 months old) bGH transgenic mice resemble the aged 25 month old WT controls in exhibiting poor memory retention compared to young WT controls [47]. Memory retention has also been examined in a study of GHR-/- mice [11]. In this experiment, both young (2-4 months) and old (17-20 months) GHR-/- mice were examined, along with WT controls. The test performed consisted of applying an equivalent foot shock to the mice (adjusted for the reduced size of GHR-/- animals) as they entered a compartment. Memory retention and resulting avoidance was measured at 24 hours, 7 days and 28 days after the initial shock. After 24 hours, there was no significant difference in avoidance behavior between the four groups, but by 7 days, the old WT mice showed a decline in memory retention compared to the young WT mice. This decline in avoidance was even more pronounced at the 28 day time point. Old GHR-/- mice, on 
the other hand, did not show any such decline in memory retention compared to young GHR-/- or WT mice [11]. Therefore, it is concluded that memory retention is improved in old mice with absent or impaired GH signaling, suggesting not only that GH is not necessary for memory formation and retention, but also that the absence of GH signaling has beneficial effects on memory retention.

Further analysis was conducted by performing a water maze test with young and old WT and GHR-/- mice [13]. In this experiment, spatial learning and memory were measured by recording the time taken to repeatedly swim to a hidden under water platform from different starting locations at different intervals following a training regimen. Old WT animals had lower spatial learning and memory performance than young WT controls, while the old GHR-/- mice performed as well as young animals of both genotypes. While the mechanism of GH's effects on cognition are unknown, $\mathrm{GH}$ has been postulated to correlate with the activity and concentration of certain neurotransmitters in the cerebrospinal fluid (CSF) that may be involved. For example, a study of 24 patients with adult onset GH deficiency showed that rhGH administration caused a decrease in the CSF concentration of homovanillic acid (a metabolite of dopamine) and an increase in aspartate (an excitatory neurotransmitter involved in memory processing from the hypothalamus)[48].

The experimental observations described above indicate a putative role of GH in memory performance and cognition. Further investigations using animal models of altered GH action and human subjects will be helpful in defining the role of $\mathrm{GH}$ in the brain and the molecular mechanism behind this effect.

\section{GH DYSREGULATION AND THE HUMAN BRAIN: ACROMEGALY, GHD AND LARON SYNDROME}

The study of GH function in the human brain presents many unique obstacles. Deijen and Arwert review these difficulties [49]. In order to assess an individual's cognitive function, many branches of cognition must be addressed. Inherent to this assessment is the first problem: comparison among studies is difficult, as different batteries of exams are used to assess cognitive function. Secondly, differences among sampled patient populations might represent a confounding factor. For example, within GHD patients, isolated GH deficiency (IGHD) is often a disease that begins in childhood and manifests chronically while adult onset GHD (AO-GHD) is more acute, often due to a pituitary tumor, pituitary surgery, radiotherapy, or physical trauma to the head. This means that in AO-GHD other pituitary hormone levels are affected concurrently. Finally, there is the problem of ensuring an adequate control group. Most studies reference normal healthy individuals as a control group, effectively leading to open, non-placebo controlled, non-blinded studies.

In addition to procedural limitations, other difficulties lie in the complex biochemical effects of GH. For example, GH is known to increase the peripheral conversion of thyroxin (T4) to the more biologically active triiodothyronine (T3), inhibit 11-beta hydroxysteroid dehydrogenase 1 (11-BHSD) which is responsible for the conversion of cortisone to cortisol, and enhance overall androgen production [49]. Elevated T3 levels have been linked to obesity [50], while changes in T3 levels have been associated with depression [51]. On the other hand, high levels of 11-BHSD1 are expressed in areas of the brain known to affect cognition such as the hippocampus and prefrontal cortex, and increased levels may play a role in depression $[52,53]$. Also, local aromatization of testosterone to estrogens in the brain has been implicated in sex specific effects on cognition and higher level functions [54].

Hyper GH secretion after cessation of vertical growth and loss of a diurnal GH secretion pattern characterize acromegaly. Clinically, the most commonly presented symptoms are coarsened facial features, enlarged hands and feet, hypertension, and macrognathia [55]. Acromegaly and its effects on brain function are reviewed by Werner [56]. In short, there are no documented improvements in cognition due to chronically increased GH secretion. Additionally, there have been no reports of increased psychiatric morbidity or depression in patients with newly diagnosed, untreated acromegaly. What has been documented is a decrease in the quality of life in patients with acromegaly, probably due to the changes in habitus, decreased motility, and decreased energy levels. Interestingly, approximately $30 \%$ of patients with acromegaly also exhibit hyperprolactinemia which has been shown to decrease libido and cause difficulty in concentration and memorization. Finally, acromegaly patients have increased risk of neuropathies due to hypertrophy of perineural and endoneural tissue. One striking example is a case study report of a patient presenting with symptoms of both acromegaly and the rare Chiari-I malformation, likely due to neural covering and bony tissue changes from increased GH secretion [57].

While hypersecretion of $\mathrm{GH}$, as evidenced by acromegaly patients, has yet to show any detrimental effects on cognition, studies on GHD patients demonstrate mixed results, with some studies indicating subnormal cognition and others reporting normal or enhanced cognition. One randomized, double-blind, placebo-controlled study in 40 male AO-GHD patients showed that after 18 months of GH replacement there were no significant improvements in cognition [58]. Deijen and Arwert [49] provide a thorough review on the cognitive status of AO-GHD patients. In general, AO-GHD patients show a decrease in attention and concentration with increased forgetfulness. Long term studies indicate a subnormal IQ. A meta-analysis of literature between 1985 and 2004 reported patient outcomes in GHD adults after GH replacement therapy [59]. Out of 15 studies in the meta-analysis only four reported data on cognitive function. Of these four, only two studies were placebo controlled. Results demonstrated improvement in patient-reported outcomes after 3, 6 and 12 months of GH replacement when compared to baseline. When compared to placebo, however, no significant improvement was recognized. Furthermore, cognitive function, after a median GH treatment duration of 6 months, also showed no significant improvement. Due to lack of controlled studies, 
however, the effect of GH replacement on cognitive function was not compared to placebo. The authors conclude that further analysis is necessary to not only differentiate between CO-GHD and AO-GHD, but also to distinguish the effects of IGF-1 from those of GH in a standardized and controlled study [59].

Laron syndrome, or primary GH insensitivity, is caused by mutations in the gene coding for the GHR or in genes encoding proteins involved in intracellular signaling downstream of the receptor. Clinically, patients present just as those with IGHD with the only difference being that Laron patients will have high serum $\mathrm{GH}$ and undetectable IGF-1 levels. In a review by Laron [60], brain growth and motor development were delayed in Laron syndrome patients. MRI and CT scans showed various degrees of tissue loss, from normal to diffuse atrophy. Mental development also varied from normal to mental retardation. Untreated patients, when compared to age matched groups, demonstrated a lower than average IQ. In this review, Laron notes that hypoglycemia in infancy may contribute to the low intelligence scores. In a more recent study, specific molecular defects in the GHR gene were correlated with phenotypical findings on brain MRI [61]. In particular, the combined deletion of exons 3,5 , and 6 was associated with cerebellar atrophy, parenchymal loss and low IQ scores, while mutations in exon 6 resulted in no abnormal findings on brain MRI and a normal IQ score. Although these associations are based on only 10 patients, these results bring light to the idea that the different genetic dysfunctions of the GHR gene potentially have distinct biological effects, the nature of which is unknown. Further study of larger cohorts of patients that includes precise genetic and molecular characterization of the GHR gene and expression products could bring a better understanding to the mechanism by which GH signaling affects brain development and function.

\section{SUMMARY}

For more than 25 years, the brain has been known to posses the capacity to bind GH [62]. Subsequent characterization has shown that both $\mathrm{GH}$ and GHR are expressed in the CNS in a temporally and spatially regulated fashion. The precise role of $\mathrm{GH}$ in the CNS has been a challenging topic to study. Much of the data gathered has been contradictory and difficult to reconcile. Studies using the GHR-/- "Laron Mouse" have provided some important clues. Brain and pituitary tissues from GHR-/- animals are larger than controls, relative to body weight, which suggests that growth of these tissues may occur in a $\mathrm{GH}$-independent manner. At the same time, morphologic changes in these tissues are evident, including changes in neural cell density. While the GHR-/- brain is significantly smaller than the WT brain in absolute weight (though larger relative to body weight), the total number of neurons was equivalent. Also, changes in the pituitary due to GHR disruption include a decrease in lactotrophs accompanied by an increase in circulating PRL levels, suggesting that intact GHR signaling is necessary to maintain normal PRL levels. Dysregulation of the complex GH mediated feedback loops in the hypothalamus and pituitary causes significant changes in somatotroph morphology in GHR-/- and dwarf GHA mice. Prenatal and perinatal motoneuron development in the GHR/- animals is nearly indistinguishable from controls by most measures taken, including spinal cord volume, muscle fiber diameter and organization as well as the number of motoneurons.

In order to use this research to further our understanding of human disease, it is helpful to contextualize the data with respect to acromegaly, GHD, and Laron syndrome, which represent primary dysfunctions of $\mathrm{GH}$ secretion and/or signaling. Supraphysiologic GH levels in acromegaly have neither proved to be beneficial nor detrimental to brain function. Some researchers believe that the emerging picture for adult GHD patients is one of impaired cognition, however, there is limited data and further study is needed [63]. In Laron patients, the variety of psychological presentations, particularly the diverse phenotypes associated with different molecular defects of the GHR gene, further confounds the role of GH in the brain. The recent production of a Cre-lox mediated GHR disruption mouse, which allows for tissue specific deletion of GHR, will allow more refined studies to be undertaken [64]. Fundamental questions regarding the role of $\mathrm{GH}$ in brain development and function remain largely unanswered, including even the most basic question of whether intact GH signaling is necessary for proper brain development and function. While much progress has been made, perhaps the data to date has generated more questions than answers. There are currently mouse models that approximate acromegaly [15], Laron syndrome [17] and GHD [16]. Further use of these and other animal models, as well as continued work with controlled studies of human patients with acromegaly, GHD, and Laron syndrome, will help elucidate the intricate role that $\mathrm{GH}$ and IGF-1 play in the development and function of the brain.

\section{CONFLICT OF INTEREST}

The authors confirm that this article content has no conflicts of interest.

\section{ACKNOWLEDGEMENT}

Declared none.

\section{REFERENCES}

[1] Lobie PE, Garcia-Aragon J, Lincoln DT, Barnard R, Wilcox JN, Waters MJ. Localization and ontogeny of growth hormone receptor gene expression in the central nervous system. Brain Res Dev Brain Res 1993 20; 74(2): 225-33.

[2] Harvey S, Johnson CD, Sanders EJ. Growth hormone in neural tissues of the chick embryo. J Endocrinol 2001; 169(3): 487-98.

[3] Harvey S, Hull K. Neural growth hormone: an update. J Mol Neurosci $2003 ; 20(1): 1-14$.

[4] Donahue CP, Kosik KS, Shors TJ. Growth hormone is produced within the hippocampus where it responds to age, sex, and stress. Proc Natl Acad Sci USA 2006 ; 103(15): 6031-6.

[5] Noguchi T, Sugisaki T, Nishikawa N, Tsukada Y. Restoration of microcephalic cerebrum with hypomyelination in the growth hormone-deficient mouse (lit): stimulatory effects of GH restricted to the first 20 days of postnatal life. Neurochem Res 1988; 13(3): 249-52.

[6] Scheepens A, Sirimanne ES, Breier BH, Clark RG, Gluckman PD, Williams CE. Growth hormone as a neuronal rescue factor during recovery from CNS injury. Neuroscience 2001; 104(3): 677-87. 
[7] Otteson DC, Cirenza PF, Hitchcock PF. Persistent neurogenesis in the teleost retina: evidence for regulation by the growthhormone/insulin-like growth factor-I axis. Mech Dev 2002; 117(12): 137-49.

[8] Ajo R, Cacicedo L, Navarro C, Sanchez-Franco F. Growth hormone action on proliferation and differentiation of cerebral cortical cells from fetal rat. Endocrinology 2003; 144(3): 1086-97.

[9] Hoddes ES. Effect of growth hormone on memory in mice. Sleep 1979; 1(3): 287-97.

[10] Thornton PL, Ingram RL, Sonntag WE. Chronic (D-Ala2)-growth hormone-releasing hormone administration attenuates age-related deficits in spatial memory. J Gerontol A Biol Sci Med Sci 2000 ; 55(2): B106-12.

[11] Kinney BA, Coschigano KT, Kopchick JJ, Steger RW, Bartke A. Evidence that age-induced decline in memory retention is delayed in growth hormone resistant GH-R-KO (Laron) mice. Physiol Behav 2001 ; 72(5): 653-60.

[12] Kinney BA, Meliska CJ, Steger RW, Bartke A. Evidence that Ames dwarf mice age differently from their normal siblings in behavioral and learning and memory parameters. Horm Behav $2001 ; 39(4): 277-84$.

[13] Kinney-Forshee BA, Kinney NE, Steger RW, Bartke A. Could a deficiency in growth hormone signaling be beneficial to the aging brain? Physiol Behav 2004; 80(5): 589-94.

[14] Forshee BA. The aging brain: is function dependent on growth hormone/insulin-like growth factor-1 signaling? Age (Dordr) 2006; 28(2): 173-80.

[15] Chen WY, White ME, Wagner TE, Kopchick JJ. Functional antagonism between endogenous mouse growth hormone $(\mathrm{GH})$ and a GH analog results in dwarf transgenic mice. Endocrinology 1991; 129(3): 1402-8.

[16] Chen WY, Wight DC, Mehta BV, Wagner TE, Kopchick JJ. Glycine 119 of bovine growth hormone is critical for growthpromoting activity. Mol Endocrinol 1991; 5(12): 1845-52.

[17] Zhou Y, Xu BC, Maheshwari HG, et al. A mammalian model for Laron syndrome produced by targeted disruption of the mouse growth hormone receptor/binding protein gene (the Laron mouse) . Proc Natl Acad Sci USA 1997; 94(24): 13215-20.

[18] Walsh RJ, Mangurian LP, Posner BI. The distribution of lactogen receptors in the mammalian hypothalamus: an in vitro autoradiographic analysis of the rabbit and rat. Brain Res 1990; 530(1): 1-11.

[19] Attardo D, Harvey S. Growth hormone-binding sites in chicken hypothalamus. J Mol Endocrinol 1990; 4(1): 23-29.

[20] Lai ZN, Emtner M, Roos P, Nyberg F. Characterization of putative growth hormone receptors in human choroid plexus. Brain Res 1991; 546(2): 222-26.

[21] Lai Z, Roos P, Zhai O, et al. Age-related reduction of human growth hormone-binding sites in the human brain. Brain Res 1993; 621(2): 260-6.

[22] Zhai Q, Lai Z, Roos P, Nyberg F. Characterization of growth hormone binding sites in rat brain. Acta Paediatr Suppl 1994; 406: 92-5.

[23] Burton KA, Kabigting EB, Clifton DK, Steiner RA. Growth hormone receptor messenger ribonucleic acid distribution in the adult male rat brain and its colocalization in hypothalamic somatostatin neurons. Endocrinology 1992; 131(2): 958-63.

[24] Kastrup Y, Le Greves M, Nyberg F, Blomqvist A. Distribution of growth hormone receptor mRNA in the brain stem and spinal cord of the rat. Neuroscience 2005; 130(2): 419-25.

[25] Sjogren K, Bohlooly-Y M, Olsson B, et al.Disproportional skeletal growth and markedly decreased bone mineral content in growth hormone receptor -/- mice. Biochem Biophys Res Commun 2000; 267(2): 603-8

[26] Ransome MI, Goldshmit Y, Bartlett PF, Waters MJ, Turnley AM. Comparative analysis of CNS populations in knockout mice with altered growth hormone responsiveness. Eur J Neurosci 2004 ; 19(8): 2069-79.

[27] McIlwain DL, Hoke VB, Kopchick JJ, Fuller CR, Lund PK. Differential inhibition of postnatal brain, spinal cord and body growth by a growth hormone antagonist. BMC Neurosci 2004; 5: 6 .

[28] Shea BT, Hammer RE, Brinster RL. Growth allometry of the organs in giant transgenic mice. Endocrinology 1987; 121(6): 1924-30.
[29] Garcia-Aragon J, Lobie PE, Muscat GE, Gobius KS, Norstedt G, Waters MJ. Prenatal expression of the growth hormone $(\mathrm{GH})$ receptor/binding protein in the rat: a role for $\mathrm{GH}$ in embryonic and fetal development? Development 1992; 114(4): 869-76.

[30] Parsons SA, Banks GB, Rowland JA, et al. Genetic disruption of the growth hormone receptor does not influence motoneuron survival in the developing mouse. Int J Dev Biol 2003; 47(1): 41-9.

[31] Turnley AM, Faux CH, Rietze RL, Coonan JR, Bartlett PF. Suppressor of cytokine signaling 2 regulates neuronal differentiation by inhibiting growth hormone signaling. Nat Neurosci 2002; 5(11): 1155-62.

[32] Frohman LA, Downs TR, Chomczynski P. Regulation of growth hormone secretion. Front Neuroendocrinol 1992; 13(4): 344-405.

[33] Kato Y, Murakami Y, Sohmiya M, Nishiki M. Regulation of human growth hormone secretion and its disorders. Intern Med $2002 ; 41(1): 7-13$.

[34] Wong AO, Zhou H, Jiang Y, Ko WK. Feedback regulation of growth hormone synthesis and secretion in fish and the emerging concept of intrapituitary feedback loop. Comp Biochem Physiol A Mol Integr Physiol 2006; 144(3): 284-305.

[35] Asa SL, Tannenbaum GS. Cell-cell communication in the pituitary: orchestrator of pulsatile growth hormone secretion? Trends Endocrinol Metab 2006 ; 17(8): 299-300.

[36] Asa SL, Coschigano KT, Bellush L, Kopchick JJ, Ezzat S. Evidence for growth hormone $(\mathrm{GH})$ autoregulation in pituitary somatotrophs in $\mathrm{GH}$ antagonist-transgenic mice and $\mathrm{GH}$ receptordeficient mice. Am J Pathol 2000; 156(3): 1009-15.

[37] Kineman RD, Teixeira LT, Amargo GV, Coschigano KT, Kopchick JJ, Frohman LA. The effect of GHRH on somatotrope hyperplasia and tumor formation in the presence and absence of GH signaling. Endocrinology 200; 142(9): 3764-73.

[38] Peng XD, Park S, Gadelha MR, et al. The growth hormone (GH)axis of $\mathrm{GH}$ receptor/binding protein gene-disrupted and metallothionein-human GH-releasing hormone transgenic mice: hypothalamic neuropeptide and pituitary receptor expression in the absence and presence of GH feedback. Endocrinology 2001; 142(3): 1117-23.

[39] Chandrashekar V, Bartke A, Coschigano KT, Kopchick JJ. Pituitary and testicular function in growth hormone receptor gene knockout mice. Endocrinology 1999; 140(3): 1082-8.

[40] Silbergeld A, Klinger B, Schwartz H, Laron Z. Serum prolactin in patients with Laron-type dwarfism: effect of insulin-like growth factor I. Horm Res 1992; 37(4-5): 160-4.

[41] Chandrashekar V, Bartke A. Influence of hypothalamus and ovary on pituitary function in transgenic mice expressing the bovine growth hormone gene and in growth hormone-deficient Ames dwarf mice. Biol Reprod 1996; 54(5): 1002-8.

[42] Eaton K, Sallee FR, Sah R. Relevance of neuropeptide Y (NPY) in psychiatry. Curr Top Med Chem 2007; 7(17): 1645-59.

[43] Donahue CP, Jensen RV, Ochiishi T, et al. Transcriptional profiling reveals regulated genes in the hippocampus during memory formation. Hippocampus 2002; 12(6): 821-33.

[44] Deijen JB, de Boer H, Blok GJ, van der Veen EA. Cognitive impairments and mood disturbances in growth hormone deficient men. Psychoneuroendocrinology 1996; 21(3): 313-22.

[45] Coschigano KT, Clemmons D, Bellush LL, Kopchick JJ. Assessment of growth parameters and life span of GHR/BP genedisrupted mice. Endocrinology 2000; 141(7): 2608-13.

[46] Brown-Borg HM, Borg KE, Meliska CJ, Bartke A. Dwarf mice and the ageing process. Nature 1996; 384(6604): 33.

[47] Meliska CJ, Burke PA, Bartke A, Jensen RA. Inhibitory avoidance and appetitive learning in aged normal mice: comparison with transgenic mice having elevated plasma growth hormone levels. Neurobiol Learn Mem 1997; 68(1): 1-12.

[48] Burman P, Hetta J, Wide L, Mansson JE, Ekman R, Karlsson FA. Growth hormone treatment affects brain neurotransmitters and thyroxine. Clin Endocrinol (Oxf) 1996; 44(3): 319-24.

[49] Deijen JB, Arwert LI. Cognitive Status of Adult Growth Hormone (GH)-Deficient Patients and GH-Induced Neuropsychological Changes. In: Nyberg F, Ed. The Somatotrophic Axis in Brain Function. Amsterdam: Elsevier Academic Press; 2006. p. 287.

[50] Reinehr T. Obesity and thyroid function. Mol Cell Endocrinol 2010; 316(2): 165-71. 
[51] Gold MS, Pottash AL, Extein I. Hypothyroidism and depression. Evidence from complete thyroid function evaluation. JAMA 1981; 245(19): 1919-22.

[52] Marques AH, Silverman MN, Sternberg EM. Glucocorticoid dysregulations and their clinical correlates. From receptors to therapeutics. Ann NY Acad Sci 2009; 1179: 1-18.

[53] Weber B, Lewicka S, Deuschle M, Colla M, Vecsei P, Heuser I. Increased diurnal plasma concentrations of cortisone in depressed patients. J Clin Endocrinol Metab 2000; 85(3): 1133-6.

[54] Gillies GE, McArthur S. Estrogen actions in the brain and the basis for differential action in men and women: a case for sex-specific medicines. Pharmacol Rev 2010; 62(2): 155-98.

[55] Cordero RA, Barkan AL. Current diagnosis of acromegaly. Rev Endocr Metab Disord 2008; 9(1): 13-19.

[56] Werner S. Acromegaly and brain function: Effects on the human brain during conditions with increased growth hormone concentrations. In: Nyberg F, Ed. The Somatotrophic Axis in Brain Function Amsterdam: Elsevier Academic Press 2006. p. 267.

[57] Lemar HJ Jr, Perloff JJ, Merenich JA. Symptomatic Chiari-I malformation in a patient with acromegaly. South Med J 1994; 87(2): 284-5.

[58] Baum HB, Katznelson L, Sherman JC, et al. Effects of physiological growth hormone $(\mathrm{GH})$ therapy on cognition and quality of life in patients with adult-onset GH deficiency. J Clin Endocrinol Metab 1998; 83(9): 3184-9.

[59] Arwert LI, Deijen JB, Witlox J, Drent ML. The influence of growth hormone $(\mathrm{GH})$ substitution on patient-reported outcomes and cognitive functions in GH-deficient patients: a meta-analysis Growth Horm. IGF Res 2005; 15(1): 47-54.

[60] Laron Z. Laron syndrome (primary growth hormone resistance or insensitivity): the personal experience 1958-2003. J Clin Endocrinol Metab 2004; 89(3): 1031-44.

[61] Shevah O, Kornreich L, Galatzer A, Laron Z. The intellectual capacity of patients with Laron syndrome (LS) differs with various molecular defects of the growth hormone receptor gene. Correlation with CNS abnormalities. Horm Metab Res 2005; 37(12): 757-60.

[62] Di Carlo R, Muccioli G. Receptors for lactogenic hormones in rabbit hypothalamus: properties and regulation. Adv Biochem Psychopharmacol 1983; 37: 429-39.

[63] van Nieuwpoort IC, Drent ML. Cognition in the adult with childhood-onset GH deficiency. Eur J Endocrinol 2008; 159 (Suppl 1): S53-7.

[64] Fan Y, Menon RK, Cohen P, et al. Liver-specific deletion of the growth hormone receptor reveals essential role of growth hormone signaling in hepatic lipid metabolism. J Biol Chem 2009 ; 284(30): 19937-44.

(C) Gosney et al.; Licensee Bentham Open.

This is an open access article licensed under the terms of the Creative Commons Attribution Non-Commercial License (http://creativecommons.org/licenses/bync/3.0/) which permits unrestricted, non-commercial use, distribution and reproduction in any medium, provided the work is properly cited. 